\title{
Physical health-related quality of life at higher achieved hemoglobin levels among chronic kidney disease patients: a systematic review and meta-analysis
}

Murilo Guedes $^{1 *}$ (D), Camila R. Guetter ${ }^{2}$, Lucas H. O. Erbano ${ }^{1}$, Andre G. Palone ${ }^{1}$, Jarcy Zee ${ }^{3}$, Bruce M. Robinson ${ }^{3}$, Ronald Pisoni ${ }^{3}$, Thyago Proença de Moraes ${ }^{1}$, Roberto Pecoits-Filho ${ }^{1,3}$ and Cristina P. Baena ${ }^{1}$

\begin{abstract}
Background: The impact of anemia treatment with erythropoietin stimulating agents (ESA) on health-related quality of life (HRQOL) in chronic kidney disease (CKD) patients is controversial, particularly regarding optimal hemoglobin $(\mathrm{Hb})$ target ranges.

Methods: We conducted a systematic review and meta-analysis of observational studies and randomized controlled trials (RCT) with ESA to estimate the effect of different achieved $\mathrm{Hb}$ values on physical HRQOL and functionality. We searched PubMed, EMBASE, CENTRAL, PEDro, PsycINFO and Web of Science databases, until May 2020. Two authors independently extracted data from studies. We included observational and RCTs that enrolled CKD patients undergoing anemia treatment with ESA with different achieved Hb levels among groups. We excluded studies with achieved $\mathrm{Hb}<9 \mathrm{~g} / \mathrm{dL}$. For the meta-analysis, we included RCTs with control groups achieving $\mathrm{Hb} 10-11.5 \mathrm{~g} / \mathrm{dL}$ and active groups with $\mathrm{Hb}>11.5 \mathrm{~g} / \mathrm{dL}$. We analyzed the standardized mean difference (SMD) between groups for physical HRQOL.

Results: Among 8496 studies, fifteen RCTs and five observational studies were included for the systematic review. We performed the meta-analysis in a subset of eleven eligible RCTs. For physical role and physical function, SMDs were 0.0875 [95\% Cl: $-0.0025-0.178]$ and 0.08 [95\% Cl: $-0.03-0.19]$, respectively. For fatigue, SMD was 0.16 [95\% $\mathrm{Cl}$ : 0.09-0.24]. Subgroup analysis showed that trials with greater achieved $\mathrm{Hb}$ had greater pooled effects sizes 0.21 [95\% Cl: 0.07-0.36] for $\mathrm{Hb}>13 \mathrm{~g} / \mathrm{dL}$ vs. 0.09 [95\% Cl: 0.02-0.16] for Hb 11.5-13 g/dL. Proportion of older and long-term diabetic patients across studies were associated with lower effect sizes.

Conclusion: Achieved hemoglobin higher than currently recommended targets may be associated with small but potentially clinically significant improvement in fatigue, but not in physical role or physical function. Younger and non-diabetic patients may experience more pronounced benefits of higher $\mathrm{Hb}$ levels after treatment with ESAs.
\end{abstract}

Keywords: Anemia, Chronic kidney disease, Health-related quality of life

\footnotetext{
* Correspondence: quedeshm@gmail.com

'Pontifícia Universidade Católica do Paraná, Imaculada Conceição, 1155, Curitiba, PR 80215-901, Brazil

Full list of author information is available at the end of the article
}

(c) The Author(s). 2020 Open Access This article is licensed under a Creative Commons Attribution 4.0 International License, which permits use, sharing, adaptation, distribution and reproduction in any medium or format, as long as you give appropriate credit to the original author(s) and the source, provide a link to the Creative Commons licence, and indicate if changes were made. The images or other third party material in this article are included in the article's Creative Commons licence, unless indicated otherwise in a credit line to the material. If material is not included in the article's Creative Commons licence and your intended use is not permitted by statutory regulation or exceeds the permitted use, you will need to obtain permission directly from the copyright holder. To view a copy of this licence, visit http://creativecommons.org/licenses/by/4.0/ The Creative Commons Public Domain Dedication waiver (http://creativecommons.org/publicdomain/zero/1.0/) applies to the data made available in this article, unless otherwise stated in a credit line to the data. 


\section{Background}

A meaningful shift to more patient-centered care has been emphasized in the management of chronic kidney disease (CKD) [1]. This has been recently highlighted in different initiatives aiming to improve patient-reported outcomes (PRO) in Nephrology, such as the Standardized Outcomes Nephrology (SONG) and The Kidney Health Initiative (KHI) [2, 3].CKD has been associated with an important burden on health-related quality of life (HRQOL), and outcomes such as limitations to perform daily activities, poor physical functioning, and fatigue have been highly valued and prioritized by patients [4-6].

Anemia is found in up to $40 \%$ of patients with advanced ND-CKD and has been associated to higher mortality and morbidity [7, 8]. In fact, lower hemoglobin $\mathrm{Hb}$ ) has been shown to be one of the potential modifiable causal factors for CKD associated fatigue, which is a multi-dimensional concept with diverse causes, ranging from social, psychological and clinical factors, that is perceived as one of the most important outcomes for CKD patients and caregivers $[9,10]$. Current recommendations for clinical management of anemia show some variation across different society guidelines. KDIGO recommendations consist in targeting $\mathrm{Hb}$ levels of 10-11.5 $\mathrm{g} / \mathrm{dL}$ in patients undergoing erythropoietin stimulating agents (ESA) treatment [11]. According to the European Renal Best Practice (ERBP), treatment should target 10$11 \mathrm{~g} / \mathrm{dL}$ ranges [12].

Such recommendations are based on results of major randomized controlled trials (RCT) of ESAs, which have not only failed to show benefits in mortality in CKD population, but could also result in increased risks of cardiovascular events when used to achieve $\mathrm{Hb}$ normalization [13]. In addition, the potential benefits for HRQOL are controversial particularly for targets of $\mathrm{Hb}$ above $9 \mathrm{~g} / \mathrm{dL}$ [14-16]. Previous systematic reviews suggested that the effect of anemia correction on HRQOL may be small, although the estimates were highly heterogeneous [17-22]. Particularly, one systematic review restricted to dialysis patients suggested that the potential benefits on fatigue of anemia correction beyond 10-12 g/dL levels are limited [23], while a more recent metaanalysis comparing ESA targets concluded that HRQOL changes following ESA treatment are not clinically meaningful [21]. These systematic reviews, however, do not distinguish between achieved vs. aimed targets and therefore have limitations to the efficacy of higher achieved $\mathrm{Hb}$ levels on HRQOL. Based on the heterogeneity of the finding in this area, KDIGO guidelines recommend the individualization of $\mathrm{Hb}$ targets aiming better HRQOL outcomes, suggesting subgroups for higher benefit, such as younger patients, despite the lack of evidence [11].
Previous studies have suggested that younger patients with fewer comorbidities may benefit more from higher $\mathrm{Hb}$ levels in terms of HRQOL, given that the threshold for manifestations of limitations may depend on basal level of activities and the degree of exposure to chronic debilitating conditions [17]. Based on these findings, individuals that are more functional may experience more pronounced benefits of higher $\mathrm{Hb}$ levels after treatment with ESAs. In this sense, along the continuum of physical dysfunction [24-27], the comorbidity-related loss of functionality may represent a turning point when the potential effects on physical HRQOL of achieving higher $\mathrm{Hb}$ levels may not translate into further gains. Consequently, in this model, $\mathrm{Hb}$ targets should be dependent on the population in which they are pursued, rather than being absolute across distinct patients [11].

We therefore designed a systematic review and metaanalysis on the efficacy of $\mathrm{Hb}$ achievement and its impact on physical HRQOL. Specifically, we hypothesized that: i) achieved $\mathrm{Hb}$ levels greater than recommended by current clinical practice (for treatment with ESAs) are associated with better physical HRQOL; ii) patients with better functionality are more likely to benefit from higher $\mathrm{Hb}$ ranges after treatment with ESAs; iii) variables associated with worse functionality among populations explain part of the heterogeneity among studies. Therefore, we conducted a systematic review and metaanalysis to evaluate the impact of different achieved $\mathrm{Hb}$ levels with ESA treatment on physical HRQOL and functionality among CKD patients.

\section{Methods}

\section{Selection criteria}

We conducted a systematic review and meta-analysis according to PRISMA guidelines and MOOSE recommendations for meta-analysis of observational studies [28, 29]. We reviewed studies among CKD patients with anemia reporting outcomes in physical HRQOL or functionality published in English, Spanish or Portuguese. Physical HRQOL was assessed by scales for which there was at least one study referenced either in the original study report or in the study protocol reporting on reliability or validity. For the meta-analysis, studies were eligible if they reported on scales consistent with the Short-Form (SF-36), including SF-36 subscales, KDQOL-36 and KDQ. Functionality was evaluated either by activities of daily living (ADL) instruments or Karnofsky status.

For experimental studies, inclusion criteria consisted of adult populations treated for anemia with ESA exposed to different $\mathrm{Hb}$ targets. Exclusion criteria included placebo-controlled groups without ESA rescue strategies reported, i.e., placebo groups without a rescue ESA dose for those with achieved $\mathrm{Hb} \leq 9 \mathrm{~g} / \mathrm{dL}$, studies with control 
group achieving hemoglobin $\leq 9 \mathrm{~g} / \mathrm{dL}$, hospitalized patients, pediatric or transplant populations, quasiexperimental studies, pre- and post-intervention studies and iron treatment RCTs.

Eligibility criteria for observational studies included adult CKD populations, hemoglobin levels or ESAs as main exposure, cohort studies and outcomes in physical domains of HRQOL or functionality. For physical HRQOL outcomes, we included only studies reporting estimates adjusted for a minimum set of confounders, including any group of comorbidities, age and eGFR. For functionality outcomes we did not exclude reports with unadjusted estimates. Studies in pediatric, transplant or hospitalized populations, cost-effectiveness, reviews, letters, case-reports, case-series and studies with less than 100 patients were excluded.

\section{Search strategy}

The search for eligible studies was performed using the databases MEDLINE, EMBASE, CENTRAL, PEDro, PsycINFO and Web of Science, until May 2020. A combination of indexing terms and free text words in each database was used to build search strategies. The detailed search strategies are presented in the Supplementary Material. Grey literature was searched by review of conference abstracts.

\section{Data extraction}

Two authors independently reviewed titles, abstracts and full reports to determine study inclusion. Disagreements in any phase were solved through discussion and a third author was consulted when needed. Two authors independently extracted data from eligible studies according to a pre-defined structure for data collection.

When more than one physical HRQOL assessment was performed during follow-up, we extracted the last reported value. Different reports from the same RCTs were included if additional information on physical HRQOL was provided. For studies with three arms - two arms comparing different targets with ESAs and one arm with placebo without rescue strategy - we included information only for the ESA arms.

\section{Risk of Bias}

Risk of bias was assessed independently by two authors. For experimental studies, the Cochrane Tool for Bias Assessment was applied. For observational studies, the risk of bias was evaluated by the modified version of NewCastle Ottawa scale (NOS) for cohort studies $[30,31]$.

\section{Clinical assumptions}

For RCTs, we assumed that achieved Hb between $10 \mathrm{~g} /$ $\mathrm{dL}$ and $11.5 \mathrm{~g} / \mathrm{dL}$ in the subgroups of patients randomized to lower targets would represent current recommended clinical practices, based on KDIGO guidelines [11]. Consequently, achieved $\mathrm{Hb}$ greater than 11.5 $\mathrm{g} / \mathrm{dL}$ in active groups are assumed to represent strategies higher than current recommendations. Moreover, we excluded studies with control group reporting mean achieved $\mathrm{Hb}$ lower than $10 \mathrm{~g} / \mathrm{dL}$, assuming that for these patients the clinical benefits of anemia treatment are established [11]. Therefore, to be eligible, studies had to report: 1) achieved hemoglobin values in lower target arms within the range of $10-11.5 \mathrm{~g} / \mathrm{dL}$, reflecting current recommended targets and 2) achieved hemoglobin values on higher target arms greater than $11.5 \mathrm{mg} / \mathrm{dL}$, thereby avoiding group overlap. Finally, we defined the proportion of patients with diabetic nephropathy reported by each trial as representative of long-term complicated diabetes, which we considered a proxy for higher risk of lower functionality. We included studies in the meta-analysis according to their achieved hemoglobin values at the time of physical HRQOL assessment in the study. When studies evaluated physical HRQOL with more than one instrument, we chose to include data on KDQOL/SF-36 whenever possible.

\section{Statistical analysis}

We performed a meta-analysis of standardized mean difference (SMD) between intervention groups, using Hedges' g, from RCTs that reported sufficiently detailed data on change from baseline physical HRQOL [32] . A minimal important difference (MID) in scales was defined as 3 points on SF-36 and 0.5 for KDQ [33, 34]. For SMD, a small difference was defined as $0.2-0.5$ points [35]. The pooled effect was estimated as a weighted standardized mean difference (SMD) for the change from baseline in scores of physical domains HRQOL between higher achieved hemoglobin vs. lower achieved hemoglobin groups in each study.

Fatigue reports from SF-36 and KQD vitality scales were analyzed together, as they have been shown to measure same fatigue dimensions [36]. We imputed standard deviations from incomplete reports, according to previously reported methods [37-39]. Sensitivity analyses were carried out. For this, we excluded the subset of studies that required imputation and rerun the analyses, checking for differences in the pooled estimates. Furthermore, we reanalyzed only the subset of studies reporting outcomes on SF-36. We undertook separate analysis for subdomains of SF-36 physical dimension - physical role, physical function and vitality. For presenting the results and for comparisons with MID boundaries defined for SF-36, we back-transformed the SMD to mean differences in SF-36 scale by multiplying the effect size in SMD by the median standard 
deviation of SF-36 for the outcome subdomain from studies presenting results with this instrument [40].

Random effects models were used to estimate the pooled effect. Between study variance was estimated by the DerSimonian-Laird estimator and the HartungKnapp adjustment was used [41-43]. Heterogeneity between studies was measured by I-square and Cochran's $\mathrm{Q}$ test was run to test the null hypothesis of homogeneity considering an alpha level of 0.10 . We explored heterogeneity by mixed effects meta-regression and subgroup analyses for outcomes with more than 10 studies contributing to pooled effect estimate [44]. The a priori specified variables to be tested in meta-regression were age, diabetic nephropathy proportion, and followup period in weeks. For subgroup analysis, achieved hemoglobin in active groups within trials (categorized as $\mathrm{Hb}$ equal to $13 \mathrm{~g} / \mathrm{dL}$ ), renal replacement therapy (RRT) and blinding for both intervention and HRQOL assessments were explored. Treatment effects-subgroups interaction was evaluated by Cochran $Q$ test for heterogeneity [45]. Publication bias was evaluated using funnel plots and small study effects were assessed by the Egger test, for outcomes with more than 10 studies contributing to analysis $[46,47]$. Trim and fill method was performed to adjust for small study effects [48]. All analyses were conducted using $\mathrm{R}$ software version 3.5.1 with the package "meta".

\section{Results}

From 8496 retrieved references from databases, a total of 23 reports [14-16, 49-68], including eighteen RCTs $[14-16,49-61,67,68]$ and five observational studies [62-66] were included in this systematic review. Three reports $[49,52,55]$ were extended results for HRQOL outcomes from main clinical trials $[16,51,56]$ Therefore, fifteen independent RCTs were included. The inclusion process is depicted in Fig. 1.

\section{Characteristics of included RCTs}

All included RCTs were parallel group trials evaluating ESA treatment for anemia reporting outcomes in physical HRQOL (Table 1) [14-16, 49-61, 67, 68]. They tested different targets, which varied from 11 to $13 \mathrm{~g} / \mathrm{dL}$ to $13.5-16 \mathrm{~g} / \mathrm{dL}$ for higher target arms, whereas control group targets ranged from $9.0-12.9 \mathrm{~g} / \mathrm{dL}$. Mean achieved hemoglobin levels in control groups varied from 10.2 to $11.7 \mathrm{~g} / \mathrm{dL}$, while in higher target groups the limits were 11.7 to $14 \mathrm{~g} / \mathrm{dL}$.

Five studies included only hemodialysis patients [49-51, 54-56, 68], one included hemodialysis, peritoneal dialysis and non-dialysis individuals [57] and nine included only non-dialysis patients. The most frequently used questionnaire for quality of life assessment was SF36, followed by FACIT. Inclusion criteria varied across studies, particularly regarding the decision to include only patients with specific comorbidities, e.g. heart failure and diabetes and in the limits for variables related to iron metabolism, i.e. TSAT and ferritin. Follow-up ranged from 12 to 144 weeks.

\section{Risk of bias assessment for RCTs}

For RCTs, risk of bias differed considerably (Supplementary Figure1). Six studies had high risk of bias for incomplete data analysis criteria, mainly because patients contributing to HRQOL data were a subgroup from the randomized population, either due to attrition (e.g. high rates of loss to follow-up or mortality) or missing baseline assessments for some groups. Few studies reported assumptions for dealing with missing data, such as imputation methods, or clarified the number of patients in which HRQOL was assessed.

\section{Analysis of physical function and physical role}

Few trials reported data on Physical Function and Physical Role subdomains of SF-36. Thereby, only six studies contributed to analyses for both dimensions $[15,16,52$, $55,56,58,60]$. All studies used SF-36 for these HRQOL domains. The weighted SMD for physical function was 0.08 [95\% CI: $-0.03-0.19]$ and for physical role, 0.09 [95\% CI: - $0.0025-0.18$ ], with a significant amount of heterogeneity in both analyses (Figs. 2 and 3).

\section{Analysis of fatigue domain}

Eleven studies were eligible for meta-analysis of fatigue $[14-16,49-58,60]$. From these, nine used SF-36 vitality subscale, and the remaining used the KDQ questionnaire. In these studies, achieved hemoglobin in control groups ranged from $10.5-11.5 \mathrm{~g} / \mathrm{dL}$, and in higher hemoglobin arms it varied from 11.7 to $13.5 \mathrm{~g} / \mathrm{dL}$. The weighted SMD between groups for fatigue was 0.16 [95\% CI: $0.09-0.24$ ], with $\mathrm{I}^{2}=38 \%$ (Fig. 4). The point estimate, on SF-36 vitality scale, would be 3.2 [95\% CI: 1.8-4.2]. Studies that reported mean achieved $\mathrm{Hb}$ higher or equal than $13 \mathrm{~g} / \mathrm{dL}$ estimated higher effect sizes compared to lower achieved Hb studies: 0.21 [95\% CI: 0.08-0.35] and 0.09 [95\% CI: 0.02-0.16], respectively. The results were still significant after sensitivity analysis including only studies using SF-36 and excluding studies that required imputation.

Mixed effect meta-regression results are presented in Table 2. The proportion of patients with long-term complicated diabetes, mean age from included populations and follow-up time for HRQOL assessment were associated with lower estimated effect sizes in the analysis (Figs. 5 and 6). Subgroup analyses are presented in Table 3. Neither RRT nor blinding of participants and outcome evaluators were associated with effect modification. 


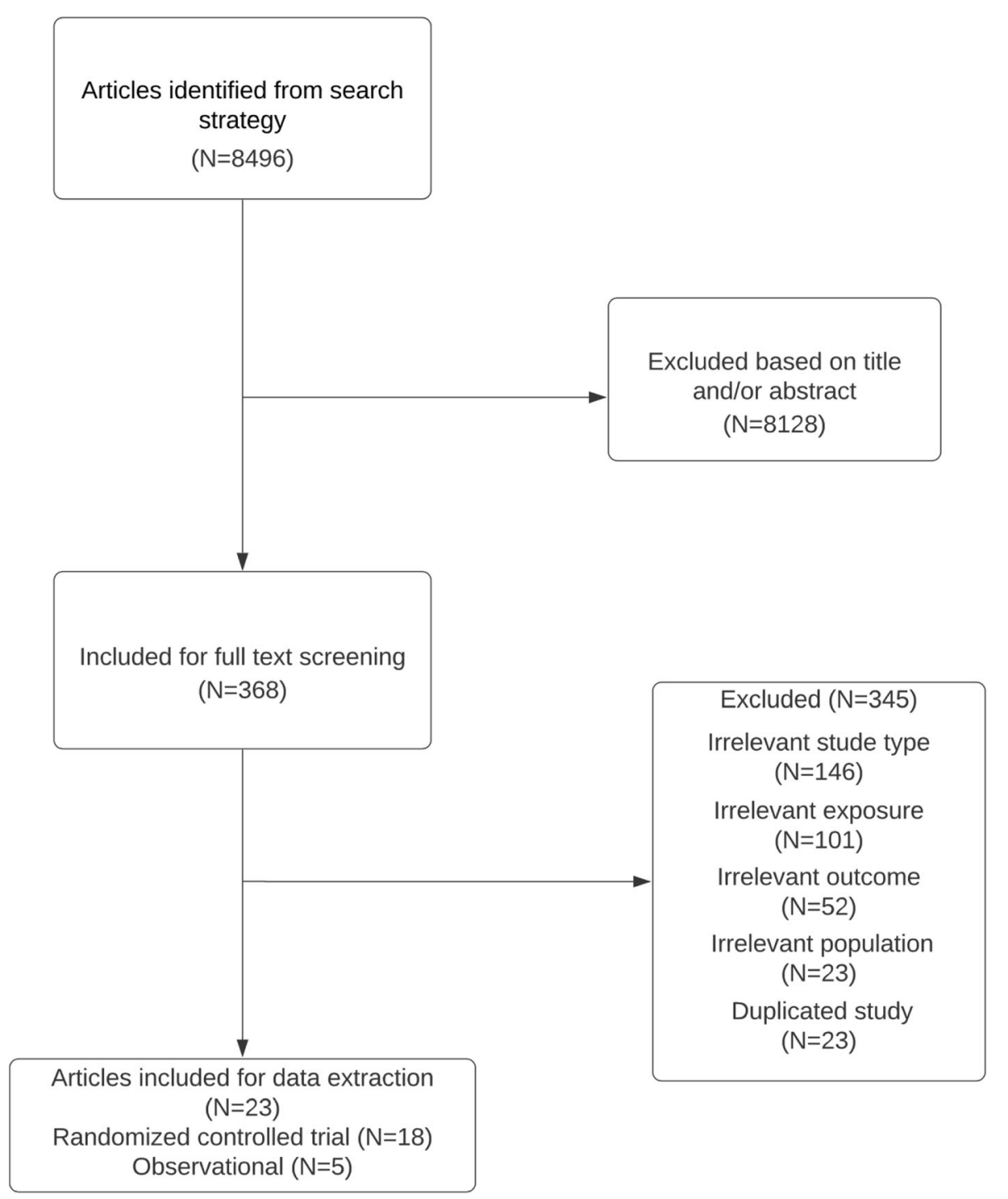

Fig. 1 Flow chart of included studies

The funnel plot for the fatigue outcome (Fig. 7) suggested asymmetry on visual inspection, which was confirmed in the Egger test $(p=0.014)$. Adjusting for potential small study effects using trim and fill method, the SMD between groups was reduced to 0.10 [CI 0.010.19], representing 2 [95\% CI: $0.2-3.8$ ] points difference on the SF-36 vitality scale.

\section{Functionality}

One RCT included functionality as a secondary outcome, assessed by the Katz scale [61]. Due to early termination, the study reported that analysis on ADLs was not possible given the lack of variation in this variable.

\section{Characteristics of observational studies}

Five cohort studies were included in the systematic review (Table 4) [62-66]. Two studies evaluated the effect of different $\mathrm{Hb}$ levels on HRQOL outcomes $[63,65]$, one assessed the impact of different ESA doses and iron prescriptions on HRQOL [66], and another two approached the influence of anemia on functionality outcomes $[62,64]$.

Two studies included dialysis patients $[65,66]$, whereas the remaining one enrolled individuals not on RRT with different glomerular filtration rates. Mean age ranged from 59 to 84 years, mean hemoglobin varied from 10.4 to $12.3 \mathrm{~g} / \mathrm{dL}$ and the minimum and maximum follow-up periods were 12 and 26 months respectively. The SF-36 questionnaire was the instrument used in all 


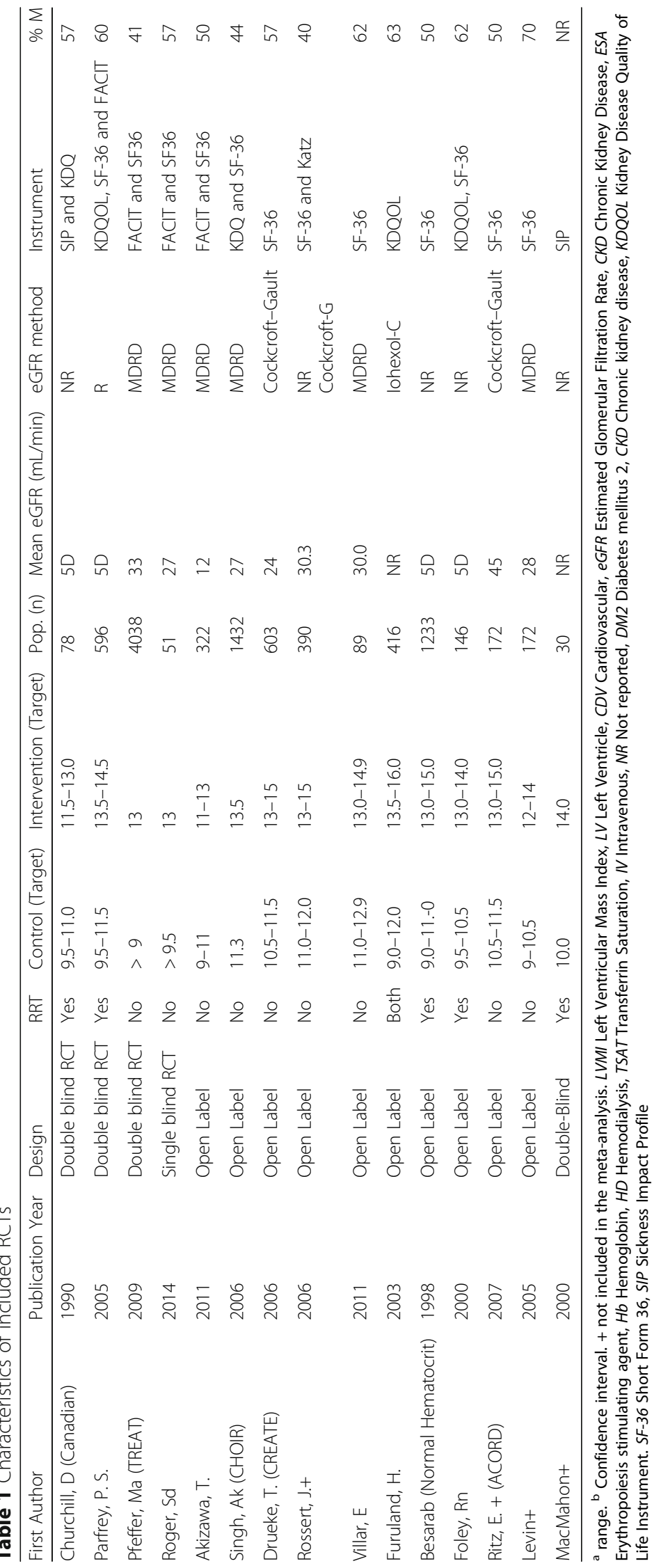




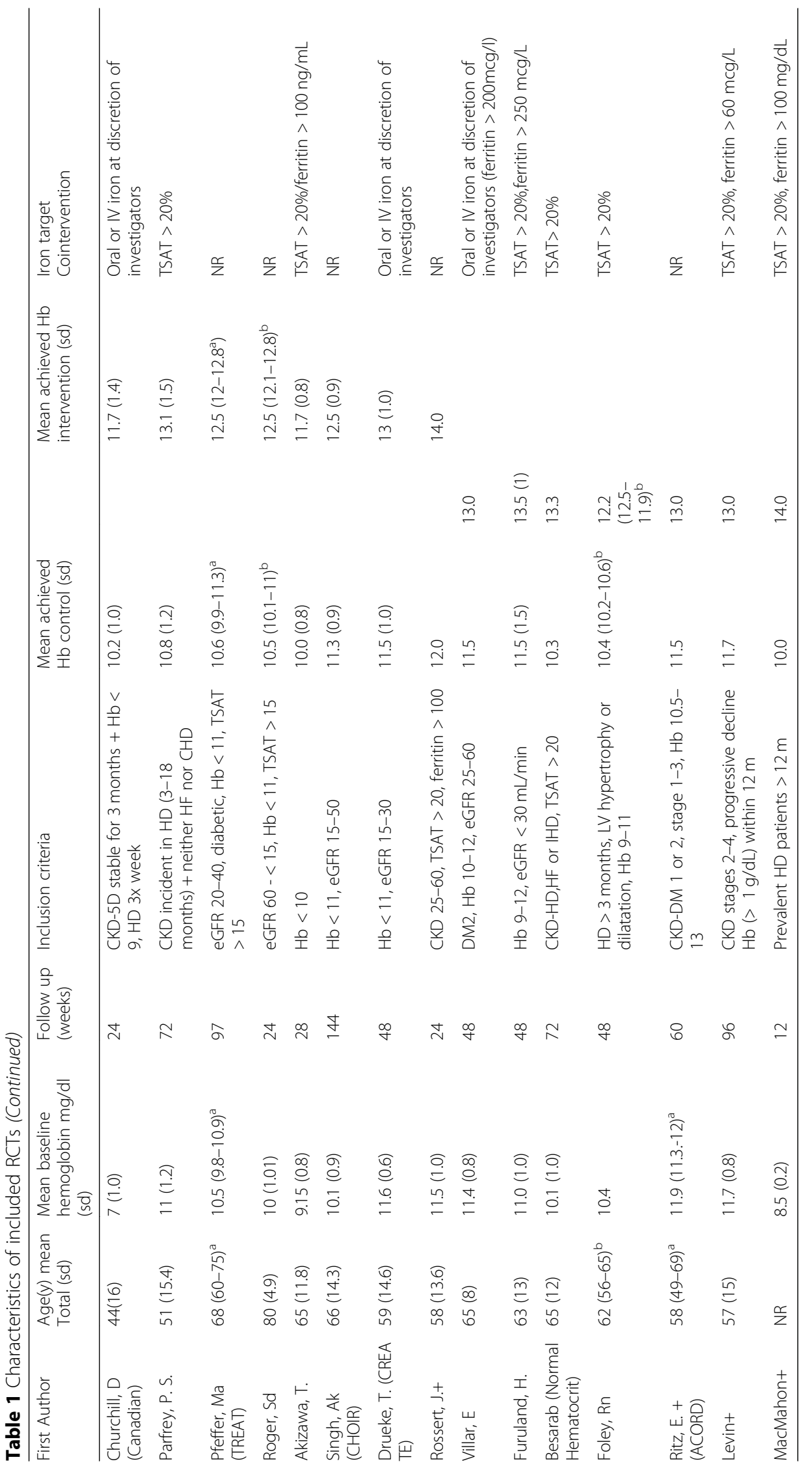




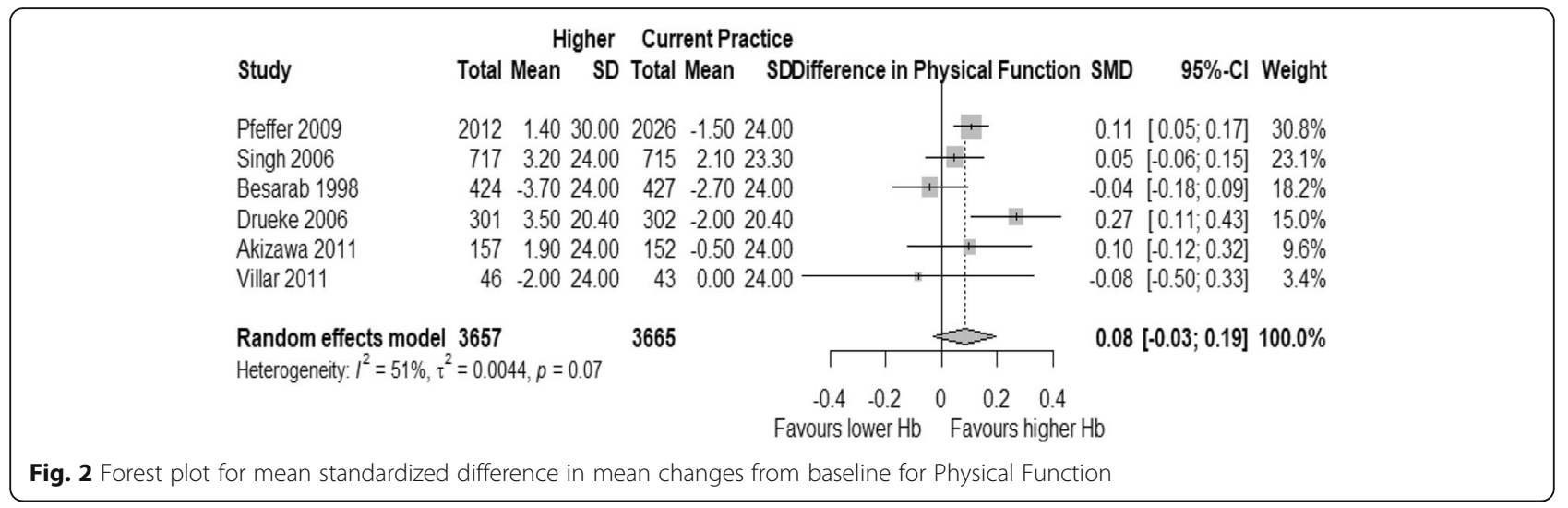

studies examining HRQOL. For assessments of functionality, the Barthel Index was used by one study while the ADLs were defined by the Minimum Data Set for assessment of nursing residents in the other study.

\section{Risk of bias in observational studies}

The quality score of observational studies varied from 2 to 8 points. Two studies achieved the maximum scores on quality assessment, both investigating the effects of different achieved hemoglobin levels on HRQOL. Apart from studies addressing functionality as an outcome, all analyses were adjusted for defined sets of potential confounders, including comorbidities, sex, age, renal function and anemia treatment.

\section{Summary of observational studies for physical HRQOL}

The two studies comparing different hemoglobin values on HRQOL outcomes were prospective studies, enrolling 809 individuals, with different patient characteristics $[63,65]$. One study included incident hemodialysis individuals followed for 12 months, while the other one enrolled patients from pre-dialysis care, followed for 24 months. Both studies reported positive associations between $\mathrm{Hb}$ and physical HRQOL, with different effect sizes. In the study including hemodialysis patients, the mean difference in comparison groups $(\mathrm{Hb} \geq 11 \mathrm{~g} / \mathrm{dL}$ vs.
$\mathrm{Hb} \leq 11 \mathrm{~g} / \mathrm{dL}$ ) did not reach MID for Physical Composite Score (PCS), whereas individual subdomain differences physical functioning and role physical - were reported to be greater than MID. Using continuous variable analyses, this study estimated a positive association between $\mathrm{Hb}$ and physical HRQOL with additional benefits beyond $12 \mathrm{~g} / \mathrm{dL}$. The study composed by pre-dialysis individuals reported overall effect sizes higher than MID for SF-36 in PCS and vitality, comparing patients with $\mathrm{Hb}$ between $11 \mathrm{mg} / \mathrm{dL}$ and $12 \mathrm{mg} / \mathrm{dL}$ with $\geq 13 \mathrm{mg} / \mathrm{dL}$. The subgroup analysis in this report suggested that the benefit was greater for younger patients who received ESAs.

The retrospective study evaluating the impact of ESAs doses and iron prescription included 13,039 hemodialysis patients [66]. Overall, patients in the lowest tercile of ESA doses did not demonstrate different HRQOL for PCS score compared to individuals in the highest tercile. Subgroup analysis showed a difference between groups among patients with hemoglobin $\leq 11 \mathrm{~g} / \mathrm{dL}$ on baseline. However, the effect size was lower than MID.

\section{Functionality}

Two observational studies stratified patients by anemia status and estimated associations on functionality outcomes [62, 64]. None of them provided

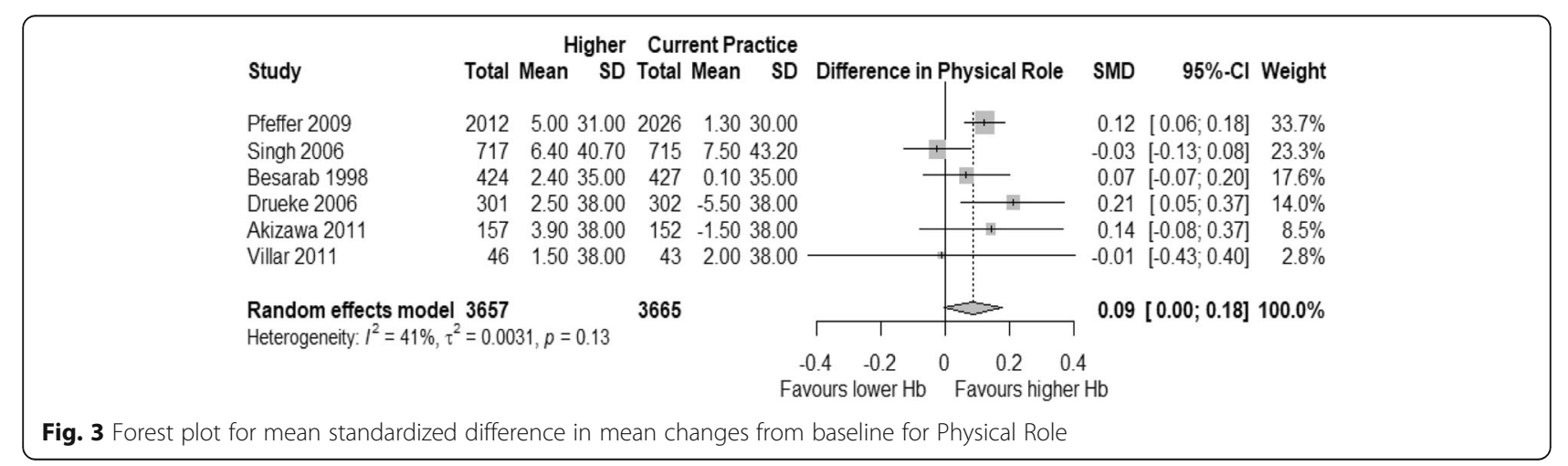




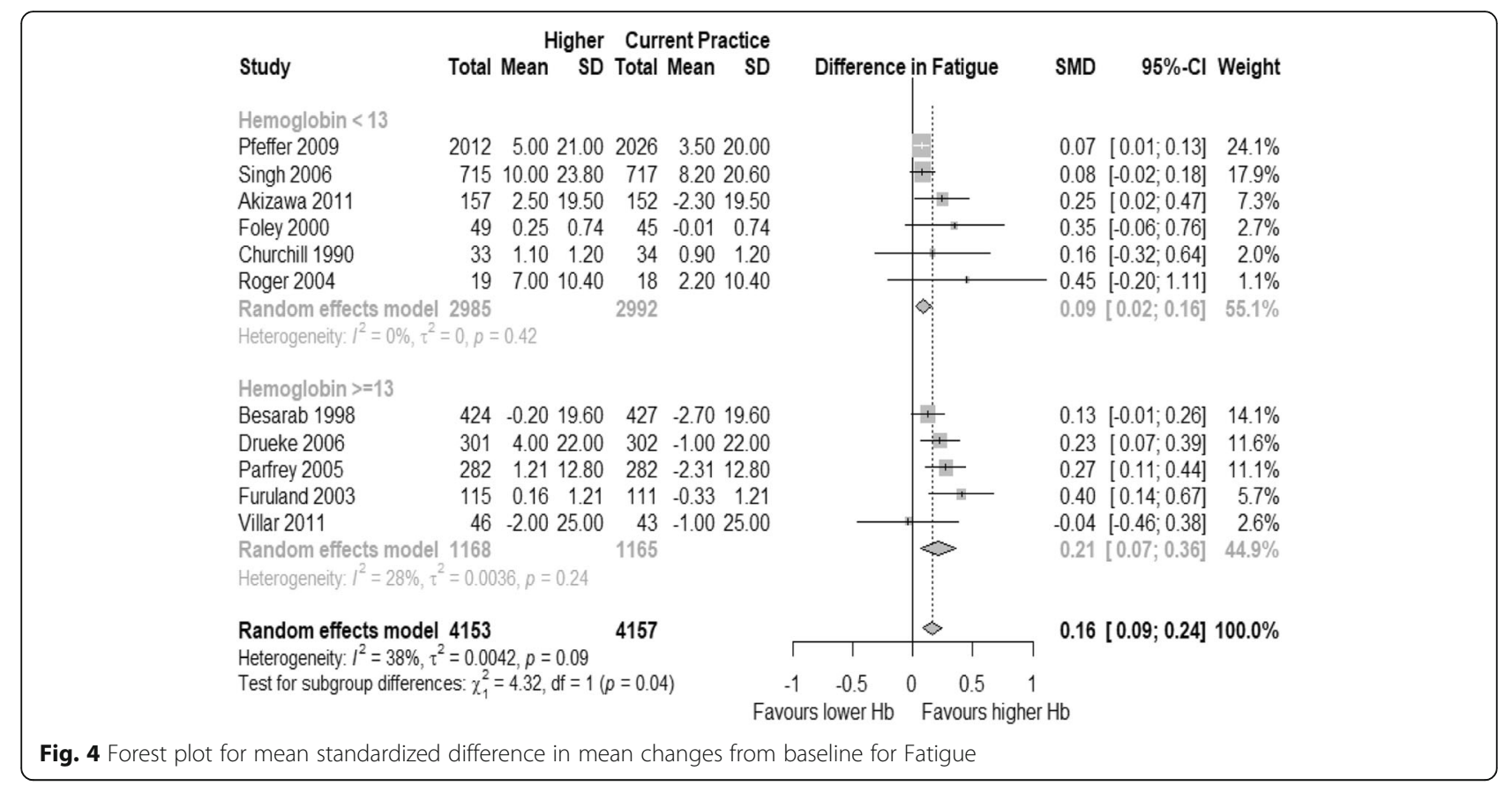

adjusted estimates for the association between anemia and limitations for ADLs. The retrospective study reported that the proportion of patients requiring assistance for ADLs was higher among anemic patients, while the prospective study estimated that the Barthel index was lower among anemic CKD individuals.

\section{Discussion}

In this systematic review and metanalysis of real-world practices on achieved $\mathrm{Hb}$, we found that fatigue - but not physical function and physical role - may be improved at hemoglobin ranges beyond the current practice recommended targets in CKD patients treated with ESAs. Our subgroup analyses and meta-regression showed that the benefit may be higher for younger patients and those free from long-term complicated diabetes. To our knowledge, this is the first evidence suggesting flexible targets for this population using only high-quality studies.

The main result of this systematic review and metanalysis was that achieved hemoglobin within 11.7-13.5 g/dL is associated with a small but clinically significant benefit for fatigue compared to current target ranges

Table 2 Mixed effect meta-regression for fatigue outcome

\begin{tabular}{lllll}
\hline Variable & Beta & SE & Confidence Interval & $p$ value \\
\hline Diabetes & -0.007 & 0.002 & $-0.01--0.003$ & 0.0003 \\
Follow up (weeks) & -0.002 & 0.0007 & $-0.003--0.0004$ & 0.009 \\
Age & -0.01 & 0.005 & $-0.01--0.0007$ & 0.03
\end{tabular}

SE Standard error recommended by guidelines of $10-11.5 \mathrm{~g} / \mathrm{dL}$. The subgroups of RCTs reporting achieved $\mathrm{Hb}>13 \mathrm{~g} / \mathrm{dL}$ on follow-up demonstrated higher effect sizes for changes in fatigue, suggesting that incremental benefits in fatigue could be associated with higher $\mathrm{Hb}$ values, although the effects are modest in magnitude. This was also suggested by the prospective cohort studies included in this review, in one case particularly for younger patients treated with ESAs with $\mathrm{Hb}>13 \mathrm{~g} / \mathrm{dL}[63,65]$.

We hypothesized that underlying factors within populations from studies would be effect modifiers [69]. Specifically, we hypothesized that conditions leading to disability, e.g. age and comorbidities, would reduce the impact of hemoglobin on physical HRQOL [63, 70] . Our analysis seems to support this model, since both age and proportion of patients with long-term diabetes important predictors of disability [71] - were associated with lower effect sizes for $\mathrm{Hb}$ differences on fatigue.

Importantly, different assumptions about the relations between variables could lead to distinct interpretations. For instance, achieved $\mathrm{Hb}$ could be seen as a mediator of the association between age/comorbidities and improvements in fatigue at higher than current target $\mathrm{Hb}$ levels, for these variables are predictors of ESA responsiveness [72, 73]. Another possibility is that age and proportion of patients with long-term diabetes are proxies for underlying risks within these populations when exposed to ESAs, which would lead to negative effects on fatigue through cardiovascular outcomes [73, 74]. Additionally, longer follow-up time for HRQOL assessment was associated with lower effect sizes. This might 


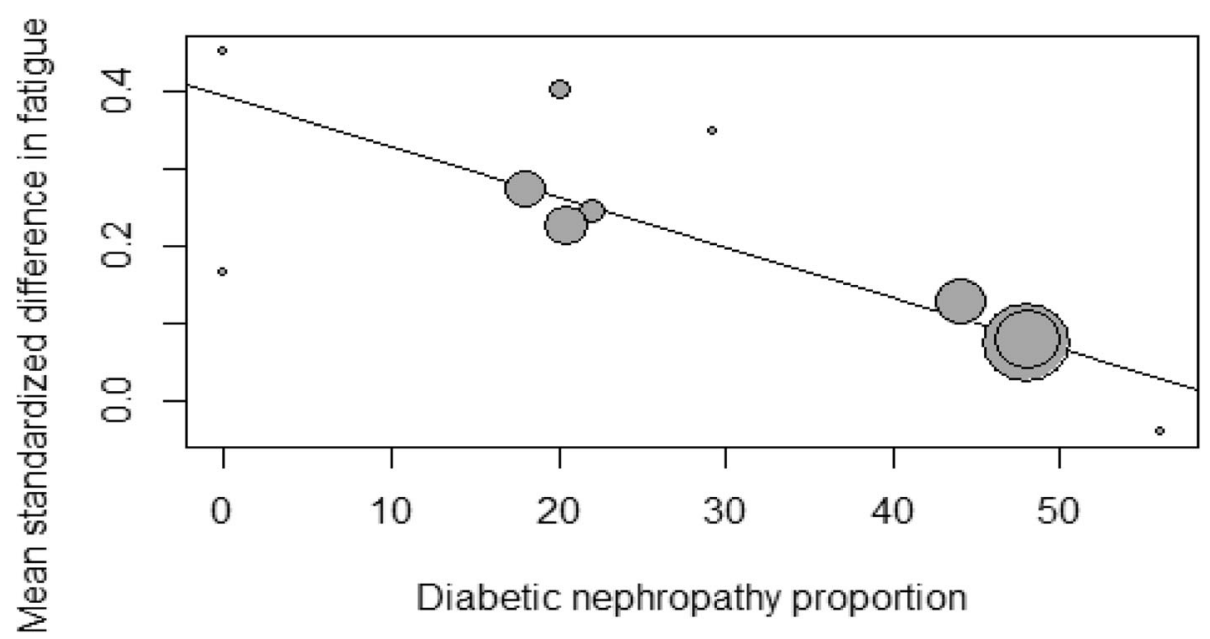

Fig. 5 Mixed effects meta-regression of diabetic nephropathy proportion and effect sizes for mean standardized differences in fatigue

suggest that the effect of $\mathrm{Hb}$ on fatigue may reduce over time, which could result from adverse effects from ESAs or the progressive disability over time [51].

The subset of studies evaluating functionality had generally low quality and demonstrated that the association between disability on ADLs and hemoglobin remains underexplored in well-designed studies [62, 64]. Independency is one of the most important outcomes for patients and families $[1,75]$, and CKD has been associated with worse functional outcomes, particularly after starting RRT [76].

Previous systematic reviews evaluated the impact of ESAs on general HRQOL, including physical components [20-22]. Collister and colleagues estimated that the effect on several HRQOL domains of patients treated for higher targets with ESAs are lower than MID for SF-
36 compared to lower targets [21]. In that study, they included reports that compared both different ESAs targets and ESA versus placebo with no rescue strategy, therefore including a subgroup of patients with severe anemia [21]. Achieved $\mathrm{Hb}$ ranges for higher and lower targets groups overlapped and the resulting estimates were highly heterogeneous, as acknowledged by the authors [21]. As achieved $\mathrm{Hb}$ differs from designed target for a set of RCTs, probably because of different distributions of ESA responsiveness and adherence to protocol, clinical interpretation of aggregate estimates in this context may be difficult. By design, our study provided estimates contrasting different achieved $\mathrm{Hb}$ to provide clear counterfactuals.

The current boundaries for hemoglobin values are defined for safety reasons that were specifically based on

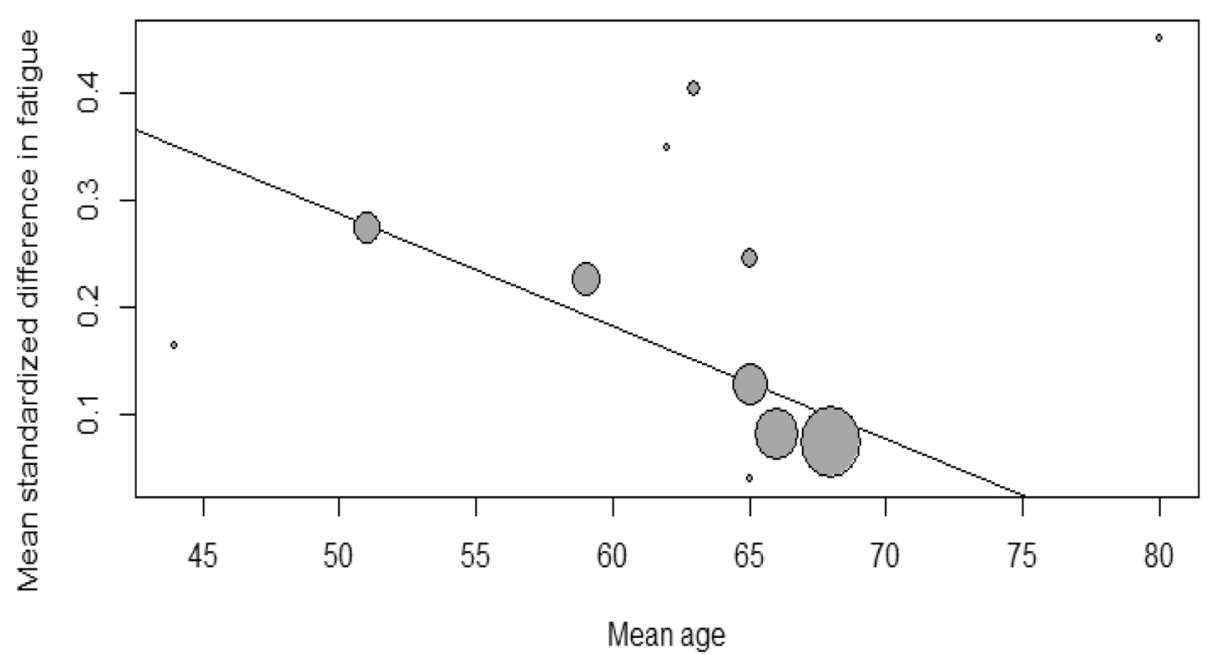

Fig. 6 Mixed effects meta-regression of mean age and effect sizes for mean standardized differences in fatigue 
Table 3 Subgroup analysis for fatigue outcome

\begin{tabular}{llllll}
\hline Variable & Yes (effect size) & Yes (n studies) & No (effect size) & No (n studies) & $P$ value \\
\hline Blinding & 0.17 & 4 & 0.17 & 7 & 0.95 \\
RRT & 0.23 & 5 & 0.11 & 6 & 0.06 \\
\hline
\end{tabular}

$R R T$ Renal replacement therapy. Effect sizes: mean standardized differences for mean changes from baseline for Fatigue in subgroups. $P$ values for Cochran's $\mathrm{Q}$ test

the ESA trials [11]. However, along with the development of new drugs for treatment of CKD anemia, such as the recently published trials on the HIF-stabilizers $[77,78]$, and the advances in characterizing distinct populations at risk, a renewed approach toward flexible targets could lead to modest, but important benefits for patients on fatigue outcomes $[79,80]$.

This study presents important limitations. Clinically, the $\mathrm{Hb}$ ranges we set to study are not recommended in current clinical practice, given the well-established risks associated with aiming $\mathrm{Hb}$ targets beyond $11.5-12 \mathrm{~g} / \mathrm{dL}$ with available interventions [11]. In light of the personcentered value care paradigm, some patients may accept higher risks aiming to attain better physical HRQOL [8], thereby yielding greater autonomy in an informeddecision model $[2,3]$. However, our study did not provide additional information on risks associated higher $\mathrm{Hb}$ targets, which have been summarized in other studies [13]. Moreover, ESAs effects on physical HRQOL could occur through different significant mediators, which would limit the inferences from the estimates we presented. For instance, the magnitude of the impact of cardiovascular events caused by ESAs on HRQOL, particularly for fatigue, and the extension to which they are independent of $\mathrm{Hb}$ variation remains unknown [74, 81]. However, under the hypothesis that non-erythropoietic effects of ESAs could be associated with lower physical
HRQOL mediated by cardiovascular events [82, 83], the pooled estimates for $\mathrm{Hb}$ effects would presumably be underestimated.

Some points about fatigue assessment should be acknowledged, which is the subdomain of physical HRQOL more associated with anemia and CKD [36]. Fatigue is a multidimensional concept that is assessed by distinct instruments and each one may evaluate a diverse set of dimensions $[5,36]$. We only evaluated, for the meta-analysis, studies using KDQOL/SF-36 and KDQ questionnaires, which have been both shown to measure the same dimensions within the fatigue framework but may have different psychometric properties [36]. Remarkably, the SF-36 vitality scale, although often used both in RCTs and observational studies, has been shown to lack content validity for hemodialysis patients [36]. This raises questions about the meaning of fatigue assessment in this population [36]. The development of broader, more reliable and valid instruments for CKD patients and especially for anemia symptoms may provide better consistency in estimates for clinical practice [84].

Methodologically, some limitations should be further noted. We could not define subsets of studies according to strict $\mathrm{Hb}$ ranges. However, the achieved $\mathrm{Hb}$ levels in control groups in ESA target trials reflects current clinical practice recommendations for anemia management

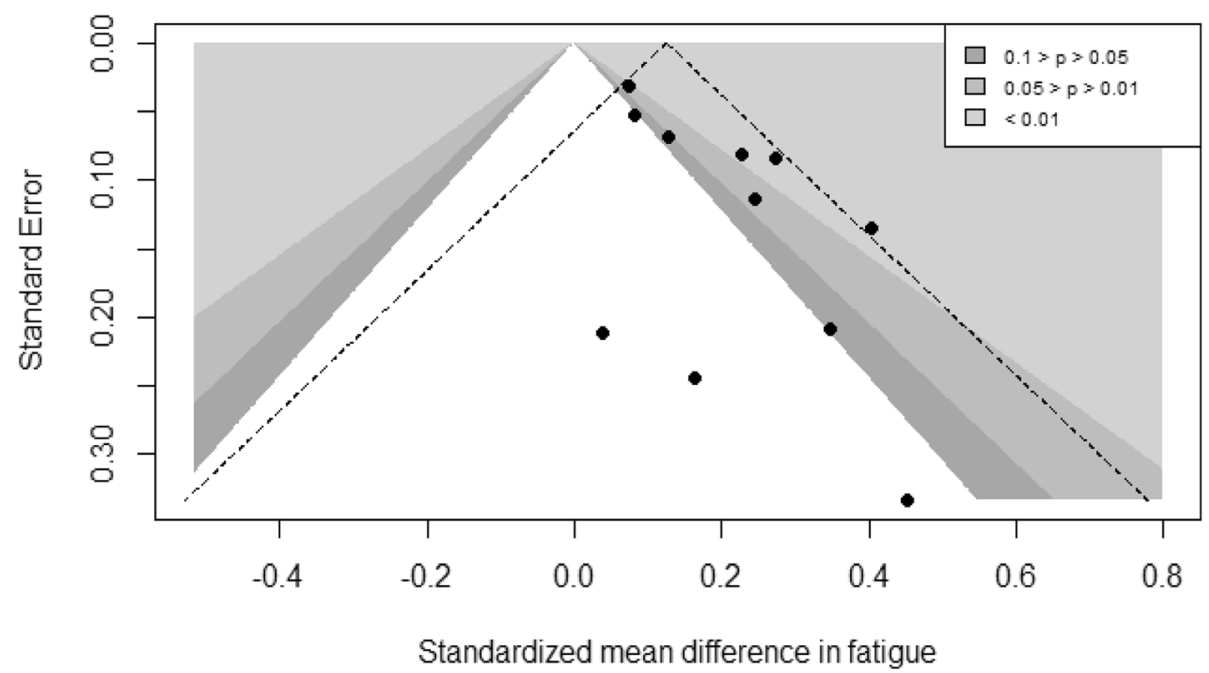

Fig. 7 Contour funnel plot for standardized mean differences in fatigue. Shaded areas correspond to different $p$ values given the standard error for assumed fixed effect 


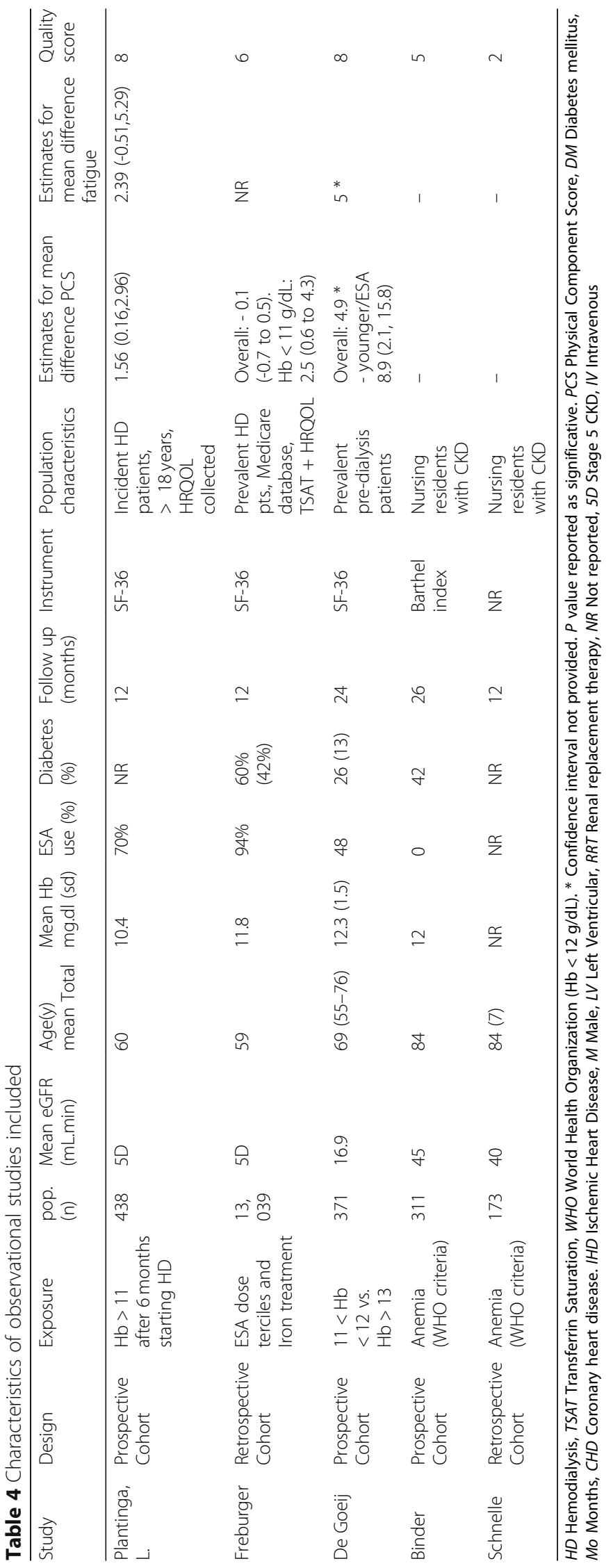


[11]. Studies often assessed physical HRQOL in subgroups of the randomized population [85]. Imputation assumptions were often not declared and any association between the frail population within these studies, with higher rates of missing data, and effect size would lead to distinct estimates from the true effect [85]. Under the assumption that frail patients benefit less from hemoglobin differences on physical HRQOL the estimates presented here would be oversized. Additionally, we extracted the last reported valued on follow-up when multiple assessments of physical HRQOL were available, as the interest of the analysis was on sustained effects on real-world achieved Hbs resulting from ESA intervention. This decision, although consistent with a more pragmatic approach for measuring the effects we were interested in, could result in more heterogeneity in the effect estimates. Finally, our meta-analysis was restricted to the population of CKD patients receiving ESAs, therefore our results could not be generalized beyond this subgroup.

Our study shows relevant strengths. We included only studies in which populations are representative of current clinical practice in terms of $\mathrm{Hb}$ ranges, in order to provide meaningful counterfactuals for $\mathrm{Hb}$ differences in physical HRQOL estimates, thereby assessing potential efficacy of achievement of $\mathrm{Hb}$ on these outcomes. As a consequence, our estimates presented low to moderate heterogeneity, particularly for fatigue. We could further explore the heterogeneity in distinct subgroups according to pre-specified variables dictated by an a priori defined model. We also provided estimates for publication bias for fatigue outcomes, which demonstrated significant small study effects in this literature.

\section{Conclusions}

In summary, achieved hemoglobin higher than currently recommended targets may be associated with relatively modest improvement in fatigue. The lack of robustness to publication bias adds a limitation to the significance of our findings, which should be interpreted with caution. Younger and non-diabetic patients may experience more pronounced benefits of higher $\mathrm{Hb}$ levels after treatment with ESAs [11]. The present study suggests the recommendation for individualization of anemia management may yield improvements on the patient prioritized fatigue symptom [11]. Further intervention studies evaluating risks and benefits of higher achieved $\mathrm{Hb}$ on physical HRQOL for subgroup of patients with lower risk of adverse events, particularly with new interventions for CKD anemia, are needed to provide better information for patient-centered informed decisions on clinical management of CKD anemia.

\section{Supplementary information}

Supplementary information accompanies this paper at https://doi.org/10. 1186/s12882-020-01912-8.

\section{Additional file 1.}

\section{Abbreviations}

LVMI: Left Ventricular Mass Index; LV: Left Ventricle; CDV: Cardiovascular; eGFR: Estimated Glomerular Filtration Rate; CKD: Chronic Kidney Disease; ESA: Erythropoiesis stimulating agent; Hb: Hemoglobin; HD: Hemodialysis; TSAT: Transferrin Saturation; IV: Intravenous; NR: Not reported; DM2: Diabetes mellitus 2; CKD: chronic kidney disease; KDQOL: Kidney Disease Quality of Life Instrument; SF-36: Short Form 36; SIP: Sickness Impact Profile

\section{Acknowledgements}

Not applicable.

\section{Authors' contributions}

The design and conduct of the study was performed by: MG, CRG, CPB, RPF, RBM, RLP, and TPM. The data collection and analysis for this study was performed by: $L H O E, C R G, A G P, M G$, and JZ. The interpretation, drafting and revision of this manuscript was conducted by all authors. The decision to submit this manuscript for publication was jointly made by all authors and the manuscript was confirmed to be accurate and approved by all authors.

\section{Funding}

Not applicable.

\section{Availability of data and materials}

The datasets used and/or analysed during the current study are available from the corresponding author on reasonable request.

Ethics approval and consent to participate

Not applicable.

Consent for publication

Not applicable.

\section{Competing interests}

There are no financial or non-financial competing interests from the authors.

\section{Author details}

${ }^{1}$ Pontifícia Universidade Católica do Paraná, Imaculada Conceição, 1155, Curitiba, PR 80215-901, Brazil. Universidade Federal do Paraná, Curitiba, Paraná, Brazil. ${ }^{3}$ Arbor Research Collaborative for Health, Ann Arbor, MI, USA.

Received: 10 February 2020 Accepted: 26 June 2020

Published online: 08 July 2020

\section{References}

1. Urquhart-Secord R, Craig JC, Hemmelgarn B, Tam-Tham H, Manns B, Howell $\mathrm{M}$, et al. Patient and caregiver priorities for outcomes in hemodialysis: an international nominal group technique study. Am J Kidney Dis. 2016;68(3): 444-54

2. Tong A, Craig JC, Nagler EV, Van Biesen W. Composing a new song for trials: the standardized outcomes in nephrology (SONG) initiative. Nephrol Dial Transplant. 2017;32(12):1963-6.

3. Archdeacon P, Shaffer RN, Winkelmayer WC, Falk RJ, Roy-Chaudhury P. Fostering innovation, advancing patient safety: the kidney health initiative. Clin J Am Soc Nephrol. 2013;8(9):1609-17.

4. Evans RW, Manninen DL, Garrison LP, Hart LG, Blagg CR, Gutman RA, et al. The quality of life of patients with end-stage renal disease. N Engl J Med. 1985;312(9):553-9.

5. Artom M, Moss-Morris R, Caskey F, Chilcot J. Fatigue in advanced kidney disease. Kidney Int. 2014;86(3):497-505.

6. Hays RD, Kallich JD, Mapes DL, Coons SJ, Carter WB. Development of the kidney disease quality of life (KDQOL) instrument. Qual Life Res. 1994;3(5): 329-38.

7. Wong MMY, Tu C, Li Y, Perlman RL, Pecoits-Filho R, Lopes AA, Narita I, Reichel H, Port FK, Sukul N, Stengel B, Robinson BM, Massy ZA, Pisoni RL, 
CKDopps Investigators. Anemia and iron deficiency among chronic kidney disease stages 3-5ND patients in the Chronic Kidney Disease Outcomes and Practice Patterns Study: often unmeasured, variably treated. Clin Kidney J. https://doi.org/10.1093/ckj/sfz091.

8. Hoshino J, Muenz D, Zee J, et al. Associations of Hemoglobin Levels With Health-Related Quality of Life, Physical Activity, and Clinical Outcomes in Persons With Stage 3-5 Nondialysis CKD. J Ren Nutr. 2020;510512276(19)30414-5. https://doi.org/10.1053/j.jrn.2019.11.003.

9. Finkelstein $\mathrm{FO}$, Finkelstein $\mathrm{SH}$. Assessing fatigue in the ESRD patient: a step forward. Am J Kidney Dis. 2018;71(3):306-8.

10. Jhamb M, Weisbord SD, Steel JL, Unruh M. Fatigue in patients receiving maintenance dialysis: a review of definitions, measures, and contributing factors. Am J Kidney Dis. 2008;52(2):353-65.

11. Group KDIGOKAW. KDIGO clinical practice guideline for Anemia in chronic kidney disease. Kidney Int Suppl. 2012;2:279-335.

12. Locatelli F, Covic A, Eckardt $K$, Wiecek A, Vanholder $R$, on behalf of the ERAEDTA ERBP Advisory Board. Anaemia management in patients with chronic kidney disease: a position statement by the Anaemia Working Group of European Renal Best Practice (ERBP). Nephrol Dial Transplant. 2009;24(2): 348-54.

13. Palmer SC, Navaneethan SD, Craig JC, Johnson DW, Tonelli M, Garg AX, et al. Meta-analysis: erythropoiesis-stimulating agents in patients with chronic kidney disease. Ann Intern Med. 2010;153(1):23-33.

14. Singh A, Szczech L, Tang K, Barnhart H, Sapp S, Wolfson M, et al. Correction of anemia with epoetin alfa in chronic kidney disease. New Engl J Med. 2006;355(20):2085-98 Available from: http://onlinelibrary.wiley.com/o/ cochrane/clcentral/articles/725/CN-00573725/frame.html.

15. Drueke TB, Locatelli F, Clyne N, Eckardt K, Macdougall IC, Tsakiris D, et al. Normalization of hemoglobin level in patients with chronic kidney disease and anemia. N Engl J Med. 2006;355(20):2071-84.

16. Pfeffer M, Burdmann E, Chen C, Cooper M, Zeeuw D, Eckardt K, et al. A trial of darbepoetin alfa in type 2 diabetes and chronic kidney disease. New Engl J Med. 2009;361(21):2019-32 Available from: http://onlinelibrary.wiley.com/ o/cochrane/clcentral/articles/122/CN-00731122/frame.html.

17. Lefebvre P, Vekeman F, Sarokhan B, Enny C, Provenzano R, Cremieux P-Y. Relationship between hemoglobin level and quality of life in anemic patients with chronic kidney disease receiving epoetin alfa. Curr Med Res Opin. 2006:22(10):1929-37.

18. Johansen KL, Finkelstein FO, Revicki DA, Evans C, Wan S, Gitlin M, et al. Systematic review of the impact of erythropoiesis-stimulating agents on fatigue in dialysis patients. Nephrol Dial Transplant. 2012;27(6):2418-25.

19. Johansen KL, Finkelstein FO, Revicki DA, Gitlin M, Evans C, Mayne TJ. Systematic review and meta-analysis of exercise tolerance and physical functioning in dialysis patients treated with erythropoiesis-stimulating agents. Am J Kidney Dis. 2010;55(3):535-48.

20. Gandra SR, Finkelstein FO, Bennett AV, Lewis EF, Brazg T, Martin ML. Impact of erythropoiesis-stimulating agents on energy and physical function in nondialysis CKD patients with anemia: a systematic review. Am J Kidney Dis. 2010;55(3):519-34

21. Collister D, Komenda P, Hiebert B, Gunasekara R, Xu Y, Eng F, et al. The effect of erythropoietin-stimulating agents on health-related quality of life in Anemia of chronic kidney disease: a systematic review and meta-analysis. Ann Intern Med. 2016;164(7):472-8.

22. Clement FM, Klarenbach S, Tonelli M, Johnson JA, Manns BJ. The impact of selecting a high hemoglobin target level on health-related quality of life for patients with chronic kidney disease: a systematic review and meta-analysis. Arch Intern Med. 2009;169(12):1104-12.

23. Jones M, Ibels L, Schenkel B, Zagari M. Impact of epoetin alfa on clinical end points in patients with chronic renal failure: a meta-analysis. Kidney Int. 2004;65(3):757-67.

24. Kittiskulnam P, Sheshadri A, Johansen KL. Consequences of CKD on functioning. Semin Nephrol. 2016;36(4):305-18.

25. Jassal SV, Karaboyas A, Comment LA, Bieber BA, Morgenstern H, Sen A, et al. Functional dependence and mortality in the international Dialysis outcomes and practice patterns study (DOPPS). Am J Kidney Dis. 2016;67(2):283-92.

26. Souza VA, Oliveira D, Barbosa SR, Correa J, Colugnati FAB, Fernandes N, et al. Sarcopenia in patients with chronic kidney disease not yet on dialysis: analysis of the prevalence and associated factors. PLoS One. 2017;12(4):e0176230.

27. Roshanravan B, Gamboa J, Wilund K. Exercise and CKD: skeletal muscle dysfunction and practical application of exercise to prevent and Treat physical impairments in CKD. Am J Kidney Dis. 2017;69(6):837-52.
28. Moher D, Liberati A, Tetzlaff J, Altman DG. Preferred reporting items for systematic reviews and meta-analyses: the PRISMA statement. Ann Intern Med. 2009;151(4):264-9 w64.

29. Stroup DF, Berlin JA, Morton SC, Olkin I, Williamson GD, Rennie D, et al. Meta-analysis of observational studies in epidemiology: a proposal for reporting. Meta-analysis of observational studies in epidemiology (MOOSE) group. Jama. 2000;283(15):2008-12.

30. Higgins JPT, Altman DG, Gøtzsche PC, Jüni P, Moher D, Oxman AD, et al. The Cochrane Collaboration's tool for assessing risk of bias in randomised trials. BMJ. 2011;343:d5928.

31. Wells G SB, O'Connell D, Peterson J, Welch V, Losos M, Tugwell P. The Newcastle-Ottawa Scale (NOS) for assessing the quality of nonrandomised studies in meta-analyses. http://www.ohri.ca/programs/_linical_ epidemiology/oxfordasp. 2013.

32. Cooper H, Hedges LV. The Handbook of Research Synthesis. New York: Russell Sage Foundation; 1994.

33. Jaeschke R, Singer J, Guyatt GH. Measurement of health status. Ascertaining the minimal clinically important difference. Control Clin Trials. 1989;10(4): 407-15.

34. Samsa G, Edelman D, Rothman ML, Williams GR, Lipscomb J, Matchar D. Determining clinically important differences in health status measures: a general approach with illustration to the health utilities index mark II. PharmacoEconomics. 1999;15(2):141-55.

35. Lydick E, Epstein RS. Interpretation of quality of life changes. Qual Life Res. 1993:2(3):221-6.

36. Ju A, Unruh ML, Davison SN, et al. Patient-reported outcome measures for fatigue in patients on hemodialysis: a systematic review. Am J Kidney Dis. 2018;71(3):327-43. https://doi.org/10.1053/j.ajkd.2017.08.019.

37. Furukawa TA, Barbui C, Cipriani A, Brambilla P, Watanabe N. Imputing missing standard deviations in meta-analyses can provide accurate results. J Clin Epidemiol. 2006;59(1):7-10.

38. Abrams KR, Gillies CL, Lambert PC. Meta-analysis of heterogeneously reported trials assessing change from baseline. Stat Med. 2005;24(24): 3823-44.

39. Higgins JPT. GSe. Cochrane Handbook for Systematic Reviews of Interventions. Chichester: Wiley; 2008

40. Schunemann HJOA, Vist GE, Higgins JPT, Deeks JJ, Glasziou P, Guyatt GH. Chapter 12: Interpreting results and drawing conclusions. Higgins JPT, Green S (editors), Cochrane Handbook for Systematic Reviews of Interventions. Chichester: Wiley; 2008.

41. IntHout J, loannidis JP, Borm GF. The Hartung-Knapp-Sidik-Jonkman method for random effects meta-analysis is straightforward and considerably outperforms the standard DerSimonian-Laird method. BMC Med Res Methodol. 2014;14(1):25.

42. Cornell JE, Mulrow CD, Localio R, Stack CB, Meibohm AR, Guallar E, et al. Random-effects meta-analysis of inconsistent effects: a time for change. Ann Intern Med. 2014;160(4):267-70.

43. Hartung J, Knapp G. On tests of the overall treatment effect in meta-analysis with normally distributed responses. Stat Med. 2001;20(12):1771-82.

44. Thompson SG, Higgins JP. How should meta-regression analyses be undertaken and interpreted? Stat Med. 2002;21(11):1559-73.

45. Borenstein M, Hedges LV, Higgins JPT, Rothstein HR. Introduction to MetaAnalysis: Wiley; 2009.

46. Lau J, loannidis JPA, Terrin N, Schmid CH, Olkin I. The case of the misleading funnel plot. BMJ. 2006;333(7568):597-600.

47. Egger M, Davey Smith G, Schneider M, Minder C. Bias in meta-analysis detected by a simple, graphical test. BMJ. 1997;315(7109):629-34.

48. Duval S, Tweedie R. Trim and fill: a simple funnel-plot-based method of testing and adjusting for publication bias in meta-analysis. Biometrics. 2000; 56(2):455-63.

49. Foley R, Curtis B, Parfrey P. Erythropoietin therapy, hemoglobin targets, and quality of life in healthy hemodialysis patients: a randomized trial. Clin J Am Soc Nephrol. 2009;4(4):726-33 Available from: http://onlinelibrary.wiley.com/ o/cochrane/clcentral/articles/404/CN-00702404/frame.html http://cjasn. asnjournals.org/content/4/4/726.full.pdf.

50. Churchill D, Keown P, Laupacis A, Muirhead N, Sim D, Slaughter D, et al. Association between recombinant human erythropoietin and quality of life and exercise capacity of patients receiving haemodialysis. Br Med J. 1990; 300(6724):573-8.

51. Parfrey PS, Foley RN, Wittreich BH, Sullivan DJ, Zagari MJ, Frei D. Doubleblind comparison of full and partial anemia correction in incident 
hemodialysis patients without symptomatic heart disease. J Am Soc Nephrol. 2005;16(7):2180-9.

52. Lewis E, Pfeffer M, Feng A, Uno H, McMurray J, Toto R, et al. Darbepoetin alfa impact on health status in diabetes patients with kidney disease: a randomized trial. Clin J Am Soc Nephrol. 2011;6(4):845-55 Available from: http://onlinelibrary.wiley.com/o/cochrane/clcentral/articles/511/CN00792511/frame.html http://cjasn.asnjournals.org/content/6/4/845.full.pdf.

53. Roger S, Jassal S, Woodward M, Soroka S, McMahon L. A randomised singleblind study to improve health-related quality of life by treating anaemia of chronic kidney disease with Aranesp ${ }^{\oplus}$ (darbepoetin alfa) in older people: STIMULATE. Int Urol Nephrol. 2014;46(2):469-75 Available from: http:// onlinelibrary.wiley.com/o/cochrane/clcentral/articles/796/CN-01121796/ frame.html https://link.springer.com/article/10.1007\%2Fs11255-013-0512-1.

54. Foley R, Parfrey P, Morgan J, Barré P, Campbell P, Cartier P, et al. Effect of hemoglobin levels in hemodialysis patients with asymptomatic cardiomyopathy. Kidney Int. 2000;58(3):1325-35 Available from: http:// onlinelibrary.wiley.com/o/cochrane/clcentral/articles/388/CN-00299388/ frame.html http://www.kidney-international.theisn.org/article/S0085-253 8(15)47224-2/pdf.

55. Coyne DW. The health-related quality of life was not improved by targeting higher hemoglobin in the Normal hematocrit trial. Kidney Int. 2012;82(2):235-41.

56. Besarab A, Bolton WK, Browne JK, Egrie JC, Nissenson AR, Okamoto DM, et al. The effects of Normal as compared with low hematocrit values in patients with cardiac disease who are receiving hemodialysis and Epoetin. N Engl J Med. 1998:339(9):584-90.

57. Furuland H, Linde T, Ahlmén J, Christensson A, Strömbom U, Danielson BG. A randomized controlled trial of haemoglobin normalization with epoetin alfa in pre-dialysis and dialysis patients. Nephrol Dial Transplant. 2003;18(2): 353-61.

58. Akizawa T, Gejyo F, Nishi S, lino Y, Watanabe $Y$, Suzuki M, et al. Positive outcomes of high hemoglobin target in patients with chronic kidney disease not on Dialysis: a randomized controlled study. Ther Apher Dial. 2011;15(5):431-40

59. Ritz E, Laville M, Bilous RW, O'Donoghue D, Scherhag A, Burger U, et al. Target level for hemoglobin correction in patients with diabetes and CKD: primary results of the Anemia correction in diabetes (ACORD) study. Am J Kidney Dis. 2007;49(2):194-207.

60. Villar E, Lièvre M, Kessler M, Lemaître V, Alamartine E, Rodier M, et al. Anemia normalization in patients with type 2 diabetes and chronic kidney disease: results of the NEPHRODIAB2 randomized trial. J Diabetes Complicat. 2011;25(4):237-43 Available from: http://onlinelibrary.wiley.com/o/cochrane/ clcentral/articles/645/CN-00811645/frame.html http://www.jdcjournal.com/ article/S1056-8727(11)00038-9/fulltext.

61. Rossert J, Levin A, Roger SD, Horl WH, Fouqueray B, Gassmann-Mayer C, et al. Effect of early correction of anemia on the progression of CKD. Am J Kidney Dis. 2006:47(5):738-50.

62. Schnelle J, Osterweil D, Globe D, Sciarra A, Audhya P, Barlev A. Chronic Kidney Disease, Anemia, and the Association Between Chronic Kidney Disease-Related Anemia and Activities of Daily Living in Older Nursing Home Residents by Schnelle et al, February 2009 Response. J Am Med Dir Assoc. 2009;10(6):444.

63. De Goeij MCM, Meuleman Y, Van Dijk S, Grootendorst DC, Dekker FW, Halbesma N. Haemoglobin levels and health-related quality of life in young and elderly patients on specialized predialysis care. Nephrol Dial Transplant. 2014;29(7):1391-8.

64. Binder EF, White HK, Resnick B, McClellan WM, Lei L, Ouslander JG. A prospective study of outcomes of nursing home residents with chronic kidney disease with and without anemia. J Am Geriatr Soc. 2012;60(5):877-83.

65. Plantinga LC, Fink NE, Jaar BG, Huang IC, Wu AW, Meyer KB, et al. Relation between level or change of hemoglobin and generic and disease-specific quality of life measures in hemodialysis. Qual Life Res. 2007;16(5):755-65.

66. Freburger JK, Ellis AR, Wang L, Butler AM, Kshirsagar AV, Winkelmayer WC, et al. Comparative effectiveness of Iron and erythropoiesis-stimulating agent dosing on health-related quality of life in patients receiving hemodialysis. Am J Kidney Dis. 2016;67(2):271-82.

67. Levin A, Djurdjev O, Thompson C, Barrett B, Ethier J, Carlisle E, et al. Canadian randomized trial of hemoglobin maintenance to prevent or delay left ventricular mass growth in patients with CKD. Am J Kidney Dis. 2005; 46(5):799-811.
68. McMahon LP, Mason K, Skinner SL, Burge CM, Grigg LE, Becker GJ. Effects of haemoglobin normalization on quality of life and cardiovascular parameters in end-stage renal failure. Nephrol Dial Transplant. 2000;15(9):1425-30.

69. VanderWeele TJ, Robins JM. Four Types of Effect Modification: A Classification Based on Directed Acyclic Graphs. Epidemiology. 2007; 18(5):561-8.

70. Leaf DE, Goldfarb DS. Interpretation and review of health-related quality of life data in CKD patients receiving treatment for anemia. Kidney Int. 2009; 75(1):15-24.

71. Porter AC, Lash JP, Xie D, Pan Q, DeLuca J, Kanthety R, et al. Predictors and outcomes of health-related quality of life in adults with CKD. Clin J Am Soc Nephrol. 2016;11(7):1154-62.

72. Szczech LA, Barnhart HX, Inrig JK, Reddan DN, Sapp S, Califf RM, et al. Secondary analysis of the CHOIR trial epoetin-a dose and achieved hemoglobin outcomes. Kidney Int. 2008;74(6):791-8.

73. Solomon SD, Uno H, Lewis EF, Eckardt KU, Lin J, Burdmann EA, et al. Erythropoietic response and outcomes in kidney disease and type 2 diabetes. N Engl J Med. 2010;363(12):1146-55.

74. Fishbane S, Besarab A. Mechanism of increased mortality risk with erythropoietin treatment to higher hemoglobin targets. Clin J Am Soc Nephrol. 2007;2(6):1274-82.

75. Evangelidis N, Tong A, Manns B, Hemmelgarn B, Wheeler DC, Tugwell P, et al. Developing a set of Core outcomes for trials in hemodialysis: an international Delphi survey. Am J Kidney Dis. 2017;70(4):464-75.

76. Kurella Tamura M, Covinsky KE, Chertow GM, Yaffe K, Landefeld CS, McCulloch CE. Functional status of elderly adults before and after initiation of Dialysis. N Engl J Med. 2009;361(16):1539-47.

77. Chen N, Hao C, Liu B-C, Lin H, Wang C, Xing C, et al. Roxadustat treatment for Anemia in patients undergoing long-term Dialysis. N Engl J Med. 2019; 381(11):1011-22.

78. Chen N, Hao C, Peng X, Lin H, Yin A, Hao L, et al. Roxadustat for Anemia in patients with kidney disease not receiving Dialysis. N Engl J Med. 2019; 381(11):1001-10.

79. Del Vecchio L, Locatelli F. Investigational hypoxia-inducible factor prolyl hydroxylase inhibitors (HIF-PHI) for the treatment of anemia associated with chronic kidney disease. Expert Opin Investig Drugs. 2018;27(7):613-21.

80. Tanaka T, Eckardt KU. HIF activation against CVD in CKD: novel treatment opportunities. Semin Nephrol. 2018;38(3):267-76.

81. Hung S-C, Lin Y-P, Tarng D-C. Erythropoiesis-stimulating agents in chronic kidney disease: what have we learned in 25 years? J Formos Med Assoc. 2014;113(1):3-10.

82. Janmaat ML, Heerkens JL, de Bruin AM, Klous A, de Waard V, de Vries CJ. Erythropoietin accelerates smooth muscle cell-rich vascular lesion formation in mice through endothelial cell activation involving enhanced PDGF-BB release. Blood. 2010;115(7):1453-60.

83. Liu Y, Xu Y, Thilo F, Friis UG, Jensen BL, Scholze A, et al. Erythropoietin increases expression and function of transient receptor potential canonical 5 channels. Hypertension. 2011;58(2):317-24

84. Tong A, Manns B, Hemmelgarn B, Wheeler DC, Tugwell P, Winkelmayer WC, et al. Standardised outcomes in nephrology - Haemodialysis (SONG-HD): study protocol for establishing a core outcome set in haemodialysis. Trials. 2015;16(1):364.

85. Colantuoni E, Scharfstein DO, Wang C, Hashem MD, Leroux A, Needham $\mathrm{DM}$, et al. Statistical methods to compare functional outcomes in randomized controlled trials with high mortality. BMJ. 2018;360:j5748.

\section{Publisher's Note}

Springer Nature remains neutral with regard to jurisdictional claims in published maps and institutional affiliations. 